\title{
Research on the characteristics and teaching strategies of international students in Higher Vocational Colleges
}

\author{
Zebang Tao \\ Guangzhou Huali Science and Technology Vocational College ,Guangzhou 510000, China \\ *Corresponding author Email:527443428@qq.com
}

Key words: Higher Vocational Colleges; international class; characteristics; teaching strategies

\begin{abstract}
International students in Higher Vocational Colleges are different from those in ordinary Higher Vocational Colleges and undergraduates. They have their own characteristics. For their teaching, in response to their characteristics on the basis of groups to take appropriate measures to promote the group's healthy and healthy development, and better training for China's international professional and technical personnel. In this paper, the international class students in Guangzhou Huali College of Science and Technology as the research object, analyze the characteristics of their groups, innovative teaching mode, put forward specific teaching strategies.
\end{abstract}

International class is to meet the global development integration and the rapid development of China's strong demand for international talent, domestic schools and foreign schools in cooperation organized by the international education system. By the domestic school commitment to the basic course teaching management, in accordance with the foreign teaching plan, syllabus and English textbooks, bilingual and English teaching model to cultivate international talents. Nowadays, most of the international classes in schools are jointly cultivated with schools in English-speaking countries, and they are trained in English and professional basic courses in China, and then go to foreign universities to finish their studies.

The international students in Higher Vocational Colleges, is a Higher Vocational Colleges which a special group, they both vocational students personality characteristics, hands-on ability, active personality active, the pursuit of self and personality publicity and so on. However, they are different from the general higher vocational students, their class number of students is small, relatively broad knowledge, vision development, exposure to new things and more.

International students in Higher Vocational Colleges and undergraduate institutions international class students are different. Undergraduate college international class students theoretical foundation is relatively deeper, basic knowledge is relatively solid, self-management and control ability. While the international classes of Higher Vocational Colleges students are strong in practical ability but weak theoretical foundation, extensive knowledge but not solid enough, self-management and control capacity is relatively weak and so on.

This paper takes the students of International Business (International Economics and Trade) Class 13, 14 and 15 as the sample, analyzes the characteristics of the group, targeted to innovative teaching mode, put forward the specific countermeasures for teaching, cultivate the special colony, promote the benign and healthy development of the group, better for our country to provide reference for the training of international composite samples.

\section{Introduction to International Class Students of Guangzhou Huali Vocational College of Science and Technology}

Guangzhou Huali College of Science and Technology approved by the Guangdong Provincial Department of Education, since 2013 with the University of Northampton in the United Kingdom to carry out international classes, mainly international business (international economy and trade) "3 +1 " project, the domestic reading 3 Year, foreign read 1 year, take the domestic specialist diploma and foreign undergraduate diploma.

College of the project enrollment plan number of 30 people each year, the actual final 
admission and admission of students is not much. Among them, 2013 level actual number of admissions and enrollment of 15 people, including 11 boys and 4girls; 2014 level a total of 8 people, including 6 boys and 2 girls; 2015 level a total of 17 people, including 14 boys and 3 girls.

Students to the main body of the Pearl River Delta region accounted for the vast majority, mainly for Guangzhou, Foshan, Dongguanand so o. In 2015, for example, a total of 17 people, including 6 people in Guangzhou, 2 people in Foshan, 2 people in Dongguan, 2 people in Huizhou and Zhuhai, Zhongshan, Jiangmen, Shantou, Maoming each 1 people. Students family economic situation is relatively good, the parents of their children's desire to become more strong [1].

\section{Analysis on the characteristics of international students in Higher Vocational Colleges}

(1) The number of international students in higher vocational colleges is small

The main reasons for the small number of international students include tuition fees, domestic tuition 25,000 yuan / year, foreign school fees 10,700 pounds / year, and other various costs. Students in the future development goals for study abroad, English requirements are high, need to achieve IELTS score 6.0, individual not less than 5.5. For the general economic status of wage earners and ordinary Higher Vocational Colleges achievement level, these are some of the relatively high threshold, leading to the international class of small number of students [2].

(2) International class of higher vocational students' personality, active and outgoing

These students are eager to learn, strong learning ability, practical ability, as long as they can stimulate their interest, they have a very strong desire and desire to explore. But they have learning inertia, all three minutes of heat, it is difficult to settle down to study theoretical knowledge, good at learning but not good at self-learning, extensive knowledge but knowledge is not solid, not systematic, teachers need to guide, sorting, systematic.

(3) Higher vocational students in the international class

International students are generally better family economic situation, have long had a computer and learn to access the Internet, have money and time to participate in a variety of tourism and activities, the surrounding environment contacts and things are relatively high-end, contact new things more early, So relatively general student knowledgeable, experience is relatively rich.

\section{The traditional teaching methods are not adapted to the international students in Higher Vocational Colleges}

First of all, the traditional teaching method is mainly teaching-oriented teaching, is to cope with the number of students more than a teaching method. Since the college enrollment, the number of classrooms in Higher Vocational Colleges is increasing year by year, from the beginning of more than 30 people a class, the development of more than 50 people a class, and later developed into two classes in class, or even three classes in class. Ordinary classroom is not suitable for use, use the big classroom, or even the ladder classroom.

Secondly, the traditional teaching methods are teacher-centered teaching. Teachers on the podium to teach the knowledge points to the teacher as the center kept saying, full house knowledge, as to whether the students can listen to it, it is difficult to say. As for students in the podium below to do other things, the teacher is difficult to put every student can be specific management in place, can manage the front three rows of students has been pretty good. And so many students, there must be different levels of learning students, teachers are more difficult to take into account the better learning and learning of poor students, can only be a moderate degree of difficulty of teaching, only moderate difficulty of the course teaching, the classroom can be a little good student to answer the one or two questions, and one or two students have been very good interaction and communication.

Again, the traditional teaching methods are more difficult to have the profound feelings of the exchange of teachers and students. 50 to 150 people in a class group, done the teachers all know, just a point before class name, clearly and completely the names of all the students point again, so that students have a sense of presence, have been spent 15 minutes. Do not say that all the students remember the name, can all students look to remember, have been very great. In fact, the entire 
class, teachers may just remember to sit in front of three rows of students, remember the more active students, remember the squad leader, learning members or disciplinary members. The establishment of the feelings of teachers and students, not only is the teaching, as well as in-depth exchanges, teachers have the personality of students to grasp the style; the students admire the personal charm of teachers and so formed.

The international class of higher vocational colleges, the number of students is small, suitable for small class teaching, suitable for group learning. Students have a relatively good foundation. They have high demands on the classroom and teachers. They want to learn not only knowledge but also different knowledge, such as international thinking, cross-cultural background and interdisciplinary knowledge. Students are not interested in traditional teaching, dare to challenge teaching authority, dare to ask questions. It can be said that our traditional teaching is the most missing thing, is the international class of students most want, most in need of things. Therefore, the traditional teaching methods can be said that the basic is not suitable for students in international classes, we must learn from learning and exploration, innovative teaching model, focusing on student-oriented teaching, is consistent with the characteristics of higher vocational students in the international community.

\section{Teaching Strategies of International Students in Higher Vocational Colleges}

That's how the teaching model is suitable for high-level international class students? In addition to the traditional teaching of a variety of teaching models, such as project teaching, goal-driven, experiential learning, cross-border learning, reverse the classroom, etc., we can learn from learning, absorbing strengths, combined with the actual teaching. But mainly to seize a key point is: for the characteristics of vocational students in international classes, mainly for students to teach. We conducted the following teaching experiments with the courses of International Trade Practice, International Marketing, and Management of Multinational Enterprises as the sample, with 13, 14 and 15 international business students as test samples.

(1) Pre-lesson learning replaces pre-lesson preparation

The traditional teaching model requires students to do pre-class preview. It is common practice for a teacher to ask students to preview the next lesson before the end of the course. This requirement is often only verbal, non-rigid requirements. The vast majority of students in essence only as an "Ear Wind", just listen to not do. And in the next lesson, the teacher how to know whether he students preview it in advance? By arranging the preparation of tasks at the same time when the layout of the problem and in the next lesson when asked. When the real to the next lesson, the teacher a question, the following a silence. The teacher asked the students to answer, it was point to the students to answer "no", "no preview", or do not prepare for the interim answer, or hesitant, and then the teacher is not embarrassing to let students sit down.

For the students of international class in higher vocational colleges, we change the traditional pre-class preview to pre-class learning. The change here is not only the change of words, but also the change of connotation. The traditional pre-class preparation only requires a general understanding of the content of the next lesson, and can not be truly in-depth understanding. And students often feel that the teacher next class will be specifically to teach, so there is no very in-depth pre-learning. Our pre-course learning, before the end of the course, clearly put forward the specific content of the next lesson before class, reference books, reference theory and point of view, a clear outline of the next lesson to answer the contents of the key points, Points of discussion. In addition to the specific requirements, we also clearly inform: written in the next class before the class to submit homework reports, the class within the same rate can not exceed $10 \%$, while the next class will be asked to answer questions, all of the above will be scored on the task of teaching students, and inform the specific standard for evaluation.

Through this innovative teaching model, aimed at the higher vocational international class students want to learn but there is learning inertia, personality Zhang Yang active and difficult to settle down at the same time study the theoretical knowledge, good at learning but not good at self-learning characteristics, in essence, forcing students in the pre-class approach through 
self-learning in a more comprehensive and in-depth study of the curriculum content again, and teachers also provide a self-learning path and method. Here, the students have the content of the course for the first time of learning, but also comprehensive, preliminary study.

(2) Classroom discussion instead of classroom study

As mentioned above, the traditional teaching method is teacher-centered teaching, may be in the process of assisted PPT, video, audio, practice, etc., but always keep in constant, which is always a teacher-centered. Teachers in the podium on the floor, students in the podium under the passive acceptance, or play mobile phones, chat, sleep and so on. Teachers can not take into account the class every classmate, to maintain the basic classroom discipline, students can have a basic response, has been a good classroom.

For the international students in Higher Vocational Colleges, we changed the traditional classroom learning to class discussion. Classroom discussion, which means that we are not in the classroom to do a comprehensive, preliminary classroom learning, this comprehensive, preliminary classroom learning we have the first step in the "pre-class learning" has been done, and the students of passive learning in order to take the initiative to learn. The classroom study to do is to test the students through the "pre-class learning" stage of the knowledge content of this lesson, the main point of view of theory, and focus on the degree of difficulty to master the assessment score. In addition, the focus of teachers through guidance, the use of teachers and students, seminars, discussion groups within the dialogue, interaction, questioning, questioning, debate and other ways, in-depth study of the points of doubt points.

Through this innovative teaching model, aimed at the small number of students in the class size, teachers have the ability, time, energy to take care of every student. For the students a wide range of knowledge, learning ability, but the knowledge is not solid, not the system, the need for teachers to guide, sorting out, systematic. Although there are scores in the research results, but the process of the study because of the presence of teachers, so students discuss the initiative and more in-depth guidance of teachers, students love for publicity, good performance, hope and recognition of the characteristics of excitation, Students' interest in courses, desire for expression and desire to explore. The whole process, through the teacher's excitation, guidance, control, so that students reach the eye, mouth, ear, brain, hands-on effect, so that students point to the course of doubt to do the second study, is in-depth, targeted learning.

(3) After class study instead of after class review

Basically, according to the traditional teaching model, to the end of the course, the teacher or the end of the course directly, the next lesson will start a new course content. Or is the beginning of the layout of the homework assignment as a review, as the next lesson reclaims most of the homework in the end is the students themselves, is the transcript, or copy students, Or is the beginning of the next lesson to look at the contents of the review, on the right when the review is.

The innovative teaching mode, has yet to solve the classroom discussion in the points of interest, to continue to discuss the doubt as the foundation, after class students are required to continue in-depth study on self, and in the next section of the course submit further study before class learning work report and submit a lesson to require students to answer the research process of the those things, those who seek help, take those methods, be that the conclusion of the study. This class of practice, but also need to hand in the research report, more in the classroom teachers to explore and inspire the desire of student learning, encourage students to take the initiative to carry out in-depth study after class.

These teaching models, in view of the student's follow suit, imitation, inertia, observation characteristics. Teachers first and second stage of strict requirements, to guide learning, stimulate interest. The third stage is still the case, beginning to end, head and tail, and each course is the case. So that students through observation, by the impact of teachers, so that students through imitation, mutual influence, so that students in-depth study to become a kind of inertia. And to this stage, the study of curriculum has been slowly evolved into the curriculum; the degree of learning produced a qualitative change, rose to a new stage. 


\section{The Effect of Creative Teaching Model}

Through teaching experiments, we found that the effect of innovative teaching is obvious. Taking the students of class 2015 of the International Business Class as an example, they produce the following changes.

(1) Improve learning initiative

Through the innovative teaching mode, the class of students learning initiative significantly improved, specifically in attendance and speech rate.

Based on the attendance rate and the rate of speaking, we mapped the changes in students' attendance (Fig.1) and the changes in student speech (Fig.2). Among them, X-axis represents the time, Y-axis represents the number.

Before the attendance rate is low, two classes before the class full attendance, with the curriculum development, the number of attendance gradually reduced. After the mid-stage, attendance has gradually picked up, to the end of the course the end of the last two classes and full attendance, see A1 curve in the Fig.1. Innovative teaching model, the first two classes before the class full attendance, not much change in the back, there may be one or two students leave, but close to full attendance, to the last two classes of course is still Manchuria, see A2 curve in the Fig.1 [3].

Before the speech rate is also low, maintained at 0 to 4 people, the whole curriculum may be no one to speak down or just learning, squad leader and studious students to speak. See B1 curve in the Fig.2. Innovative teaching model, because the teaching time is divided into five small teams, each team has been summed up, questions, speeches, and even some of the team is a student could not help but compete to add to speak, the number of speakers rose to 5 to 10 people, In the end will reach a climax. See B2 curve in the Fig.2 [4].

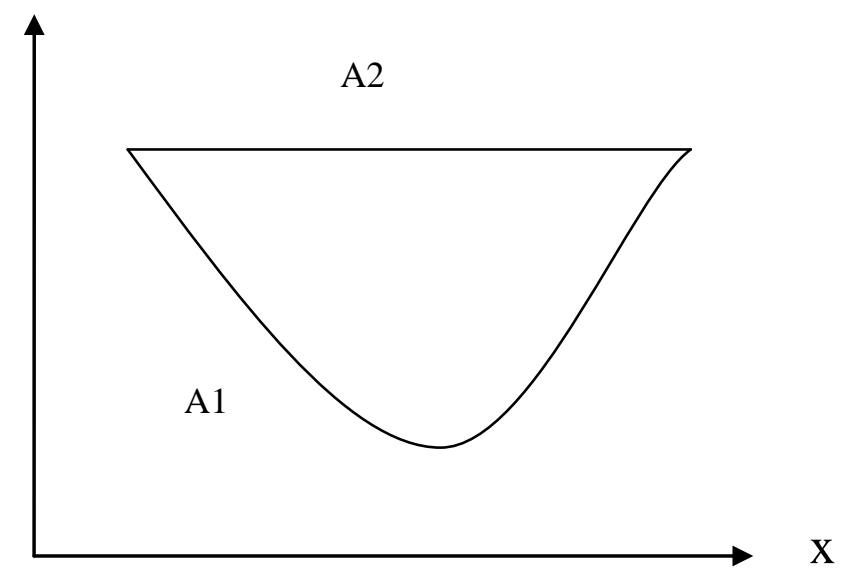

Fig.1 Student Attendance Change Chart 


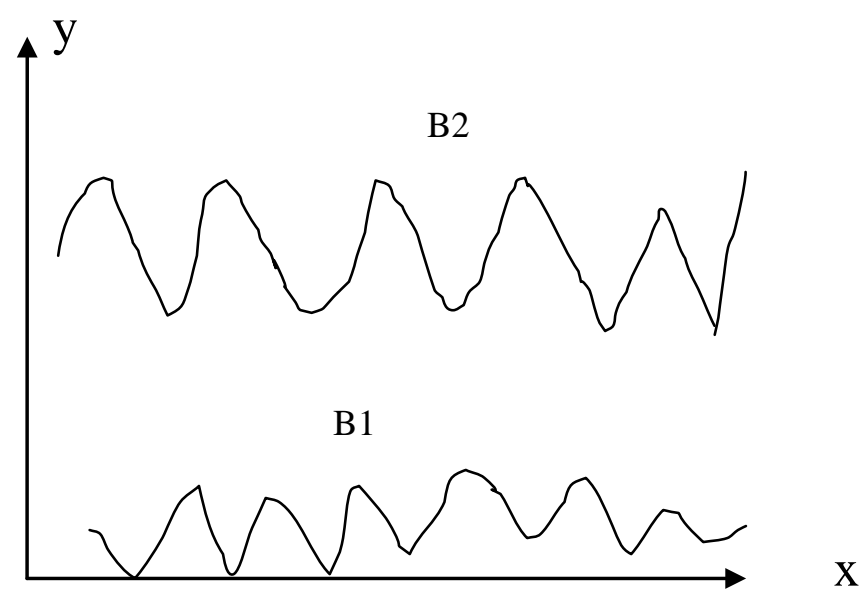

(2) Learning to deepen

Fig.2 Students speak to change the map

Through innovative teaching mode, the class of students learning to deepen, the specific performance for the breadth and depth of curriculum knowledge. Before the teaching, mainly around the textbook content, knowledge learning is mainly in the classroom, according to the situation of teachers and student performance will be slightly some expansion. Innovative teaching model, the learning content is based on textbooks as the center of outward expansion, with reference to a large number of extra-curricular reading and famous viewpoints. The study of knowledge is divided into three levels: pre-class, after-class, after-class study, in-depth study and further study. Students in-depth study of course focus, difficulty, in-depth discussion of course points, points of doubt, in-depth study of course points of interest, after a number of learning, many times to explore, many thoughts, many of the summary of knowledge is very solid and depth.

(3) Learning ability to strengthen

Through innovative teaching mode, the class of students learning ability to strengthen, the specific performance of the self-learning ability and research ability of the course. The first is self-learning ability has been greatly improved, no longer relies too much on the teaching of teachers and learning, but according to the teachers provided by the path, methods and reference materials to self-study before class. Second, in the seminar, fully mobilize the eyes, ears, mouth, head, hands and feet and other organs, receiving, output, communication information, thinking, analysis, recording, summarizing content, discussion and expression of speech is very full and in place.

\section{The deficiency of this teaching mode}

Although the innovative teaching model for high-level international class effect is very obvious, but for the time being only in the practice of more closely disciplines, such as "international trade practice", "international marketing", "multinational enterprise management" and so on. For English reading, English writing and some other theoretical strong discipline, the effect is not obvious. It is necessary to further study whether the theoretical teaching should be combined with practical teaching, whether it is to adopt other teaching models or to improve the teaching mode.

\section{Acknowledgments}

This research is supported by the following fund projects: "Research on Innovative Talents Cultivation Model of International Economy and Trade Specialty Based on Sino-foreign Cooperation" (Project No. 2014WQNCX180), which is the provincial key platform and major scientific research project of Guangdong University in 2014. In the year of 2015, Guangdong University of Quality Engineering Project "to 'turn' classroom teaching project 'and other means to 
enhance the effectiveness of classroom teaching research" (item number GDJG2015185).

\section{References}

[1] [2] Anonymous.International Exchange Center of Guangzhou Huali Vocational College of Science and Technology [EB/OL].http://www.hlxy.net/gj/

[3] [4] Anonymous. An Analysis of the International Class of Guangzhou Huali Vocational College of Science and Technology[R]. Guangzhou, Guangzhou Huali Vocational College of Science and Technology, 2016. 